\title{
ABORDARE ANTROPOLOGICĂ
}

asist. dr. arh. Anda-loana Sfinteş *; soc. mrd. antropologie Ruxandra Păduraru **

* Universitatea de Arhitectură și Urbanism „Ion Mincu”, București

** Facultatea de Sociologie și Asistență Sociala, Universitatea București

anda.sfintes@uauim.ro,ruxandra.paduraru@s.unibuc.ro

\section{Introducere}

O abordare arhitecturală centrată pe aspecte antropologice pune accent pe utilizatori, căutând să răspundă nevoilor acestora prin arhitectură. O astfel de abordare nu pleacă doar de la cunoaşterea nevoilor însă, ci mai ales de la înţelegerea în profunzime a realităţilor şi problemelor cu care actorii se confruntă, a valorilor şi identităţilor pe care şi le asumă, a modului de viaţă, aspiraţiilor, relaţiilor pe care le dezvoltă sau ar vrea să le dezvolte cu ceilalţi etc. Înţelegerea (privită drept îndepărtare de propriile preconcepţii şi valori ale viitorului arhitect/arhitectului) este un prim pas. Acesta trebuie urmat de identificarea posibilităţilor reale de intervenţie ce pot avea impact social - identificarea aspectelor asupra cărora este propice a se interveni şi a tipurilor de propuneri pertinente, urmărind responsabilitatea socială a arhitectului în relaţie cu ceea ce actorii vizaţi sunt pregătiţi (nu neapărat în mod conştient) să işi asume sau aproprieze, cu ceea ce ar însemna, pentru ei, îmbunătăţire a condiţiilor de viaţă şi de lucru, progres, dezvoltare (personală, socială, economică etc.), împuternicire [empowerment] etc. Capacitatea arhitecturii de a influenţa pozitiv comportamente (de la contribuţii în creşterea gradului de conştientizare a unor probleme sociale precum inegalitatea şi schimbarea atitudinii faţă de categoriile sociale supuse discriminării până la creşterea productivităţii la locul de muncă) se traduce, în final, în valoare a obiectului de arhitectură (Augustin \& Coleman, 2012).

Programul de arhitectură construit nu va putea răspunde niciodată nevoilor tuturor categoriilor de actori [stakeholders] identificaţi în contextul dat (utilizatorilor - drept consumatori ai spaţiului şi/sau funcţiunilor, beneficiarilor - drept actori ce vor beneficia de câştiguri de naturi diverse în urma implementării proiectului, finanțatorilor - drept categorie de actori ce dispune de resursele materiale necesare construirii etc.). Chiar şi în cazul unei aceleiași categorii de actori nevoile pot fi diverse, numeroase, uneori contradictorii sau chiar opuse. Prin urmare, definirea scopului şi obiectivelor intervenţiei de arhitectură va presupune ierarhizarea nevoilor şi asumarea (justificată) a deciziilor cu privire la nevoile adresate prin proiect.

Actori [stakeholders] - toate categoriile de beneficiari direcţi şi indirecţi (utilizatori, finaţatori, dezvoltatori etc.) asupra cărora proiectul propus are orice fel de impact, în orice măsură. 
Viitorul arhitect/arhitectul trebuie să fie conştient de faptul că arhitectura propusă poate avea implicaţii majore asupra actorilor, putând nu doar să rezolve, ci şi să accentueze sau creeze noi probleme. De exemplu, într-o perspectivă antropologică, o intervenţie arhitecturală poate contribui, prin elementele sale, la accentuarea inegalităţii sociale, inegalităţii în utilizarea spaţiului public urban, sau, din contră, la dezvoltarea unei atmosfere incluzive. Pentru a înţelege cât de fină este trecerea de la inegalitate la incluziune ne putem gândi la diferenţe în conformarea accesului într-o clădire, la acele elemente de arhitectură care pot indica oricărui trecător (1) că ceea ce se află dincolo de uşă îi este accesibil, (2) că trebuie să cunoască dinainte ce se află dincolo de uşă pentru a şti dacă poate intra, (3) că doar anumite categorii de oameni pot pătrunde în clădire. Diferenţele de mai sus nu trebuie privite ca un dat. Pentru a înţelege impactul conformării trebuie să ne gândim la ceea ce înseamnă pentru trecători, cel puţin la nivel psihic şi social, a percepe a avea sau nu drept de acces.

Totuşi, în contextul dezvoltat mai sus, flexibilitatea şi diversitatea spaţială pot deveni instrumente de arhitectură esenţiale în rezolvarea provocărilor de acest fel, instrumente care de altfel îşi găsesc corespondent în conceptele antropologice de flexibilitate şi diversitate, după cum vom vedea în paginile următoare. A nu răspunde neapărat explicit nevoilor poate crea premisele negocierii şi transformării spaţiului în loc [place-making], aproprierii [place attachment], negocierii limitelor şi utilizării spaţiului. A permite interacţiunea (directă sau indirectă) a utilizatorului cu spaţiul poate conduce la dezvoltarea creativităţii acestuia, la dezvoltarea unor noi relaţii şi la dezvoltarea unor noi valenţe ale obiectului de arhitectură prin prisma utilizării creative.

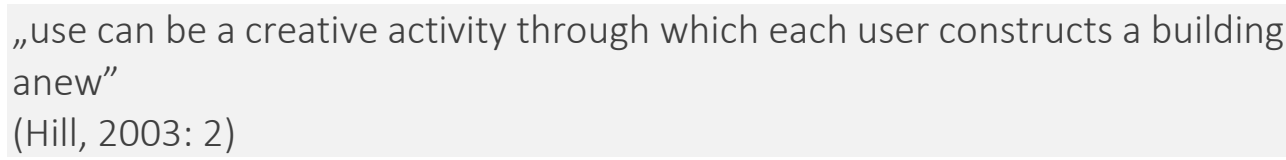

Categoriile de actori, probleme de natură socială, nevoi, relaţii în interiorul şi în afara categoriilor, dar şi tipurile de intervenţie (ca adresare a unui scop cu impact social), utilizări, rezolvări, concepte socio-antropologice şi arhitecturale potrivite contextului rezultă în urma unei cercetări temeinice.

"The reason why we research is so that we can create the best sorts of places for particular people, at particular times, doing particular things."

(Augustin \& Coleman, 2012: 45)

Cercetarea (desfăsurată pe tot parcursul procesului de proiectare) poate influenţa design-ul în diferite moduri. Urmărind influenţele identificare de Augustin \& Coleman în The Designer's Guide to Doing Research: Applying Knowledge to Inform Design (2012 Cap. 1 - Design Research and Its Influence on the Practice of Design), din punct de vedere al impactului social cercetarea poate constitui:

_ un mijloc de raportare a nevoilor la strategii de design;

un mijloc de adresare a reformei sociale - un exemplu relevant, în acest context, în reprezintă viziunea şi abordarea lui Teddy Cruz care consideră că arhitectul trebuie să îşi asume rolul de activist, contribuind, prin arhitectură, la reforme ale proceselor politice, economice, instituţionale (Cruz, 2016) ce se traduc, mai departe, în impact social; în centrul viziunii sale sunt plasate categoriile defavorizate, marginalizate, aflate în zone de conflict; 
_ un mijloc de adresare a sustenabilităţii prin conştientizarea efectului arhitecturii asupra societăţii şi mediului deopotrivă;

un mijloc de recunoaştere şi valorificare a diferenţelor culturale.

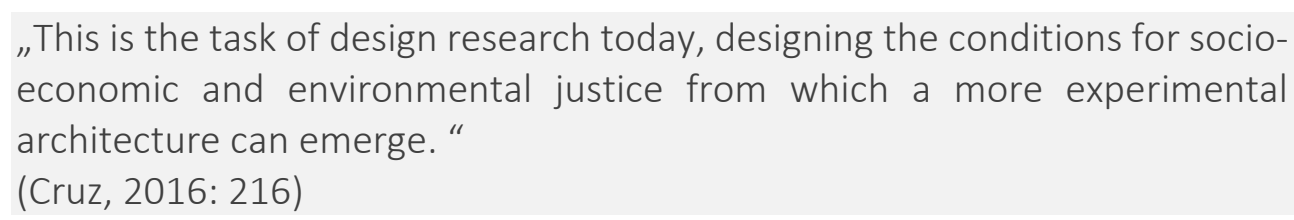

\section{Raportare la obiective didactice}

Temele-cadru de proiectare ale UAUIM fac deseori trimitere, prin obiectivele didactice stabilite pentru fiecare în parte, la analize sau cel puţin elemente de analiză antropologică. Urmărind cu precădere obiectivele didactice ale Departamentului Sinteza Proiectării de Arhitectură vom sublinia, în cele ce urmează, direcţiile ce vizează o abordare cu precădere antropologică.

Impact social. Caracteristicile obiectului de arhitectură propuse (sau determinate în urma cercetării) - de la amplasarea în contextul urban, în sit, până la conformarea volumetrică şi spaţial-funcţională - pot avea un impact pozitiv sau negativ asupra categoriilor de actori. Aceste efecte trebuie înţelese (prin raportare la realităţile cu care se confruntă actorii, privite în complexitatea lor), dar şi asumate ca urmare a conştientizării faptului că aceeaşi rezolvare poate avea impact diferit asupra unor categorii diferite de actori. Printre efectele de bază ce pot fi avute în vedere se numără, de exemplu, posibilitatea aproprierii spaţiului şi funcţiunii, posibilitatea adaptării spaţiului în timp şi/sau la nevoi diverse.

Într-o perpsectivă antropologică, interacţiunea dintre clădire şi utilizatori primează încă din faza cercetării şi abordării conceptuale. Aprecierea gradului şi tipului de flexibilitate a unei clădiri prin raportare la utilizatori poate conduce la determinarea anumitor tipuri de limite şi relaţii între spaţii, între funcţiuni, între potenţialii utilizatori. Creativitatea (capacitatea creativă a) utilizatorilor în interacţiunea lor cu spaţiul se poate transforma, în acest caz, în resursă (Hill, 2003).

Categorii de utilizatori. Analiza tuturor categoriilor de utilizatori şi înţelegerea problemelor şi nevoilor lor specifice trebuie să se facă pe baza unor cercetări corect construite. Îndepărtarea de presupuneri, păreri preconcepute, evitarea concluziilor pe baza unor date insuficiente, evitarea judecăţilor de valoare, ocolirea alegerii unor modele care nu corespund contextului local sunt obligatorii într-o abordare corectă din punct de vedere antropologic. Asumarea unei poziţii arhitecturale ar trebui să se facă doar în urma înţelegerii în profunzime a realităţilor şi problemelor majore cu care se confruntă actorii. Această poziţie asumată poate miza, chiar, pe înţelegerea rolului mediator al arhitecturii în transformări sociale. Nu trebuie pierdut din vedere, însă, faptul că deciziile asumate şi integrate în proiectare devin moduri de clasificare şi ierarhizare a nevoilor beneficiarilor, de unde rezultă responsabilitatea socială a arhitectului în faţa temei abordate şi categoriilor de oameni afectaţi prin propunere.

Relaţia public-privat. Gestionarea relaţiei public-privat (nu doar prin intermediul limitelor construcţiei propuse sau conformării accesului, ci şi prin intermediul relaţiilor facilitate, alăturării de funcţiuni etc.) este determinantă în abordarea unor concepte socio-antropologice precum: identitate/identităţi, egalitate de şanse, lupta împotriva discriminării, valori, libertate de exprimare, împuternicire (empowerment), incluziune etc. Conformarea arhitecturală poate 
încuraja sau inhiba anumite comportamente, efectele resimţindu-se la diferite scări urbane în funcţie de program şi propunere, aceeaşi clădire poate avea nu doar efecte la scară locală, ci şi la nivelul întregului oraş.

Realităţi. Fenomenul social trebuie relaţionat cu aspecte de ordin istoric, cultural, psihologic, politic, economic, tehnologic etc. pentru o înţelegere în profunzime a problemelor şi nevoilor şi identificarea unor soluţii valide. Căutarea de soluţii posibile la probleme reale, actuale, de ordin social trebuie să se facă prin raportare la istoria apariţiei şi transformării lor, la efecte psihologice atât ale problemei, cât şi ale rezolvării (înţelegerea faptului că rezolvarea propusă trebuie să poată fi apropriată de către actorii cărora le este impusă), la realitatea politică şi jocurile de putere care pot influenţa implementarea etc. Analizarea posibilităţilor reale de utilizare şi/sau apropriere a clădirii propuse trebuie raportată la cei cărora le este destinată, dar şi la celelalte categorii de actori afectaţi (pozitiv sau negativ) de prezenţa obiectului propus. Arhitectura poate avea efecte asupra culturii, economiei, sănătății fizice și psihice, relaţiilor interumane, relaţiilor de putere etc. din interiorul comunităţilor în mijlocul cărora este inserată etc. Adecvarea arhitecturii la context, din punct de vedere antropologic, se bazează pe înţelegerea relaţiei dintre actor - funcţiune - imagine arhitecturală - elemente de arhitectură.

Efecte în timp. Impactul propunerii asupra actorilor, la diferite scări, trebuie avut în vedere în timp, pe termen scurt, mediu şi lung. Anumite transformări ale nevoilor în timp pot fi preconizate, prin proiectare putându-se prevedea posibilităţi de adaptare a arhitecturii la societatea aflată într-o continuă schimbare, la transformările tehnologice rapide, sau chiar la nevoia de gestionare a situaţiilor de risc - secetă, cutremure, schimbări climatice, pandemii etc. Obiectul de arhitectură trebuie înţeles drept element cu impact - ca prezenţă arhitecturală şi funcţiune - în timp şi la diferite scări. In acest context devine foarte importantă evaluarea corectă a scării efectelor - de la scara comunităţii, la scara localităţii sau chiar scară naţională/internaţională.

\section{Cercetare - criterii, concepte}

Identităţi. Conceptul de identitate/identităţi este un concept de bază în antropologie prin intermediul cărora indivizii sau colectivităţile se identifică sau, din contră, se diferenţiază de ceilalţi. Identitatea reprezintă "sensul de sine" al unui individ, aflat într-o structură socială dată. Acesta se manifestă în comportamente, stiluri de viaţă, decizii, preferinţe etc. Identităţile sunt asumate şi comunicate celorlalţi prin intermediul unor elemente ce ţin de modurile de manifestare enumerate mai sus, dar şi atribuite individului sau comunităţii de către ceilalţi (Jaffe \& de Koning, 2016b). Prin urmare identităţile sunt construite social, depinzând nu numai de contextul în mijlocul cărora se dezvoltă, ci şi de raportul dinamic dintre modul în care indivizii vor să fie şi sunt priviţi. Identitatea este fluidă, depinde de factori exteriori; structura exterioară individului îi garantează propria identitate, prin urmare, se creează o dependență de relația cu ceilalți pentru a fi identificat. Acest raport determină inclusiv poziţionarea individului sau comunităţii în contextul urban, având impact asupra modului în care spaţiul este utilizat şi experimentat. Nu orice spaţiu, fie chiar public, este accesibil oricui. Bariere de naturi diferite, sentimentul de a te simţi sau nu bine-venit într-un spaţiu, elemente de natură politică, economică, administrativă etc. sunt motive pentru care anumite identităţi se manifestă sau nu în anumite contexte. Arhitectura poate, prin elementele sale, susţine, accentua dar se poate şi opune dreptului indivizilor şi comunităţilor de a-şi construi, exprima, negocia propria identitate într-un spaţiu. 


\begin{abstract}
„Urban lifestyles and leisure activities - from fashion, music and shopping preferences to how and where people choose to relax and socialize - are not only about economic processes or class distinction. They are also very much ways of expressing and negotiating cultural identities and political viewpoints, but, importantly, they are also ways of just having fun or even seeking an escape from everyday concerns of economy and politics."

(Jaffe \& de Koning, 2016a: 95)
\end{abstract}

Egalitate/inegalitate socială. Orice drept ce poate fi încălcat, precum şi orice acces la resurse materiale sau imateriale ce poate fi controlat, conduc la egalitate sau inegalitate (dacă este asigurat în mod discriminatoriu). Inegalitățile economice, educaționale, ocupaționale, de gen sau vârstă sunt amplificate de multe ori chiar prin elemente de design urban şi/sau arhitectură precum: proliferarea comunităţilor închise [gated communities], infrastructură ce taie accesul direct al anumitor comunităţi la servicii, imagine arhitecturală neaccesibilă, rezolvare planimetrică ce nu facilitează orientarea în spaţiu [wayfinding] sau spaţiile neadaptate nevoilor persoanelor cu disabilităţi etc. Configurările urbane şi arhitecturale pot, așadar, exacerba inegalitatea socială, dar rezolvarea incluzivă a acestora nu poate combate singură discriminarea. Lupta împotriva discriminării prin mijloace urbanistice şi arhitecturale trebuie susţinută de procese sociale de conştientizare şi combatere a stigmatului (şi invers) (Jaffe \& de Koning, 2016c). De la dreptul de a consuma sau nu un produs într-un anumit spaţiu, la dreptul de a „consuma” sau nu un spaţiu, inegalită̌ţile structurale conduc la inegalităţi urbane şi invers.

„Inequalities - of income, consumption, opportunities for mobility, degrees of security or overall life chances - are rendered especially durable in their spatial expression as patterns of segregation, inequities in physical access, disparate urban environments, differential patterns of mobility and fixity." (Tonkiss, 2013: 20)

Vorbind de sustenabilitate socială, Fermín Rodríguez Gutiérrez identifică o serie de drepturi urbane (2013: 223) care, în contextul nostru, pot fi interpretate şi privite drept surse ale egalităţii/inegalităţii:

_ dreptul de acces, acceptare şi integrare în contexte urbane diversificate, multifuncţionale şi complexe;

_ dreptul de acces la servicii şi infrastructuri (în special dreptul la mobilitate nerestricționată);

_ dreptul de a avea acces la spaţii publice de calitate ce încurajează dezvoltarea de relaţii interpersonale, construirea de comunităţi (şi identităţi);

_ dreptul de a construi şi exprima identităţi colective, de a apropria sau construi spaţii în care aceste identităţi să se poată manifesta;

_ _ dreptul de a participa în procese de luare de decizie cu privire la spaţii urbane utilizate.

O problemă precum egalitatea/inegalitatea nu poate fi rezolvată doar prin abordări arhitecturale, ci privind în perspectivă relaţii în teritoriu, relaţii între actorii implicaţi, relaţii sociale, economice, politice, istorice, culturale etc.

Diversitate şi incluziune. Manifestarea identităților diverse ale utilizatorilor într-un acelaşi spaţiu poate fi dificilă date fiind condiţiile diferite la care spaţiul trebuie să răspundă şi elementele diferite pe care trebuie să le conţină pentru a crea premisele aproprierii. În acest 
context, diversitatea şi flexibilitatea spaţială şi funç̧ională poate susţine diversitatea socială. Construirea artificială a unui spaţiu incluziv, însă, nu conduce neapărat la obţinerea unui mediu incluziv (Mendes et al., 2017), dacă nu e susţinut, de exemplu, de cadrul legislativ, administrativ, social, cultural - ce poate fi, de altfel, construit în paralel. Un spaţiu care încurajează diversitatea socială face posibil dialogul, negocierea şi astfel găsirea unui echilibru între indivizii şi comunităţile care se intersectează în spaţiul respectiv.

Este evident că jocuri de putere se pot manifesta oricând, putând conduce la răsturnarea caracterului incluziv al spaţiului. Tocmai de aceea proiectarea unui spaţiu al diversităţii şi flexibilităţii trebuie să ţină cont de multe elemente, ghidând comportamente, contribuind la educarea treptată a utilizatorilor către toleranţă, acceptare reciprocă, apoi dialog şi chiar colaborare - către un mediu incluziv. O utilizare continuă a spaţiilor publice, de exemplu, facilitată prin intermediul unei proiectări care are în vedere cadrele de timp şi activităţile în care utilizatorii au nevoie să se implice sau serviciile la care au nevoie să aibă acces devine o utilizare sustenabilă care asigură întâlnirile între oameni/comunităţi şi interacţiunea socială (vezi Stickells, 2008; Tonkiss, 2013). Astfel de intersecţii şi interacţiuni pot sta la baza unor utilizări creative care să transforme, într-un mod dinamic, atât relaţia utilizatorilor cu spaţiul, cât şi relaţii între utilizatori.

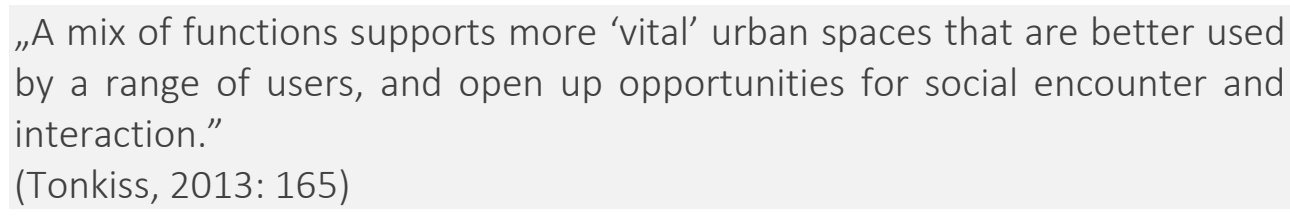

Mobilitate. Dreptul de a circula - liber şi oriunde prin oraş, către orice fel de spaţiu, servicii, facilităţi, folosind orice mijloc de transport - şi mai ales de a alege modul de a circula joacă un rol major în contextul inegalității discutate mai sus (Kuoppa, 2013). Asigurarea dreptului de a circula şi accesului, însă, nu sunt suficiente în asigurarea mobilităţii care ia în calcul şi gradul de siguranţă, gradul de confort, lejeritatea utilizării anumitor căi sau mijloace. Dincolo de restricţii impuse sau autoimpuse, mobilitatea - ca necesitate, dar şi preferinţe ce generează ritmuri urbane (Mareggi, 2013) - este strâns legată de condiţia socială, de posibilităţi (Colleoni, 2013) şi nu în ultimul rând de identitate.

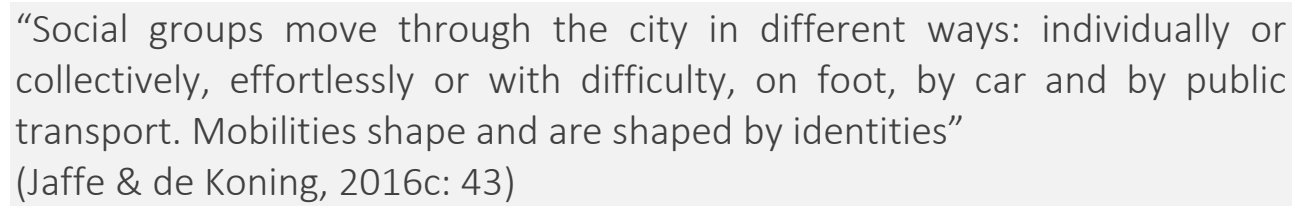

Mobilitatea constituie un element esenţial în construirea identităţii şi a relaţiilor cu ceilalţi, a relaţiilor cu spaţiul, cu oraşul nu doar prin (modul de) deplasare în sine, ci şi prin tot ceea ce se întâmplă în timpul deplasării. Timpul dedicat deplasării este încărcat de semnificaţii şi contribuie la determinarea poziţionării individului în context social urban (Miciukiewicz \& Vigar, 2013). Totodată, mobilitatea, aşa cum a fost conturată mai sus, poate sta la baza unor procese sociale importante precum emanciparea, împuternicirea, incluziunea etc.

„Different performances of movement, such as walking, cycling or bus riding, are increasingly considered emancipatory practices through which individuals gain power to renegotiate meanings of self and the city." (Miciukiewicz \& Vigar, 2013: 176) 
Caracter informal. Dincolo de cadrele instituţionale, oficiale, legale, au loc o serie de procese informale care acoperă lipsuri, satisfac nevoi de naturi diferite, doleanţe. De exemplu, economia informală se referă la orice tip de activitate ce presupune câştiguri materiale, aflată la limita sau în afara legii şi deci nemonitorizată şi neprotejată de stat. O astfel de economie poate asigura, însă, supravieţuirea categoriilor defavorizate la fel cum se întâmplă şi în cazul locuirii informale care asigură condiţii de locuit (deşi de multe ori improprii) unor oameni care nu au acces sau nu îşi permit să acceseze în mod legal forme de locuire. Pe lângă forme de comerţ sau locuire informale putem vorbi de educaţie informală, acces la servicii informale de sănătate, urbanism informal (Tonkiss, 2013) etc. O analiză a sectorului informal oferă, de fapt, o imagine a ceea ce cadrul legal nu poate acoperi sau satisface, scoate la iveală probleme profunde de ordin social, economic, negocieri ale spaţiului şi puterii. Poate evidenţia modul în care indivizi, comunităţi, societăţi îşi negociază şi rezolvă situaţii de criză. Înţelegerea mecanismelor care au dus la dezvoltarea sectorului informal poate contribui la găsirea de soluţii specifice, inovatoare. În acest context arhitectul îşi poate asuma (prin arhitectură) rolul de activist, mediind relaţia dintre cadrul formal şi cel informal, dintre politici impuse şi organicitatea unor rezolvări născute în mijlocul comunităţilor care se confruntă efectiv cu problemele vizate (Cruz, 2016).

Unele societăţi au inclus deja aspecte de ordin informal în cadrul lor legal, devenind mai flexibile şi permisive. Urbanişti şi arhitecţi (în mijlocul unor echipe interdisciplinare) proiectează bazându-se pe elemente identificate în contexte informale sau chiar pentru a accentua avantajele utilizării informale.

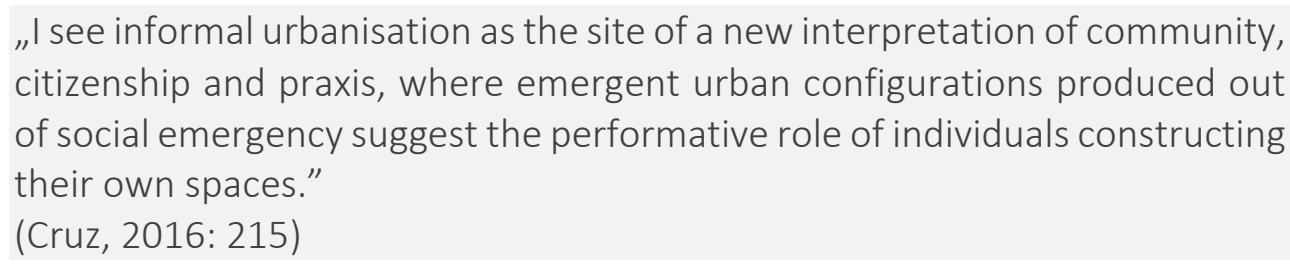

\section{Impact}

Prin proiecte de arhitectură se poate avea în vedere impactul social în mod direct (transformându-I în scop) sau indirect (prin prisma unor abordări de altă factură dar care nu ignoră posibilele efecte asupra utilizatorilor).

Impactul aşteptat este strâns legat de context şi nu poate fi pronunţat în lipsa unei cunoaşteri profunde a acestuia. Vom menţiona, totuşi, câteva scopuri pe care viitorul arhitect/arhitectul şi le poate asuma, scopuri ce pot fi atinse prin arhitectură - prin program propus, prin funcţiuni, prin relaţii între funcţiuni dar şi între interior şi exterior, prin configurare spaţială şi volumetrică, prin materiale şi sisteme implementate etc.:

_ facilitarea interacţiunii dintre actori aparţinând unor categorii sociale diferite ce activează în contextul dat urmărind dezvoltarea sustenabilităţii sociale - de exemplu, o bună gestionare a dezvoltării unei reţele locale de asigurare a accesului la bunuri şi servicii poate contribui la valorizarea muncii fiecăruia şi lupta împotriva stigmatului generat uneori de diferenţele ocupaţionale;

- adaptarea spaţiului construit la nevoile specifice ale anumitor categorii sociale - de exemplu: adresarea problemelor ridicate de munca de acasă familiilor cu copii mici în contextul pandemiei, adresarea problemelor şi nevoilor persoanelor după pensionare etc. 
_ creşterea condiţiilor de viaţă şi şanselor de dezvoltare personală - ce nu se poate face decât cunoscând statutul actual al actorilor vizaţi şi raportându-l la ceea ce ar însemna un progres adecvat, ce poate fi adresat prin elemente de arhitectură;

- revitalizarea/reactivarea spaţiului construit, transformându-I într-un spaţiu incluziv, adresat fără discriminare actorilor ce activează în contextul dat - ceea ce presupune libertatea de exprimare, de apropriere, sentimentul de siguranţă în utilizarea spaţiului;

_ regăsirea/reconstruirea unei identităţi a locului raportată la identităţile actorilor.

În perspectivă antropologică, o intervenţie arhitecturală într-un context dat trebuie să ţină cont de diversitate în complexitatea ei, să evite să contribuie la discriminare, să fie angrenată în viaţa actorilor şi totodată să angreneze procese pozitive de transformare socială, economică, politică etc., să faciliteze negocierea spațiilor, utilizărilor ca mod de găsire a unui echilibru propriu, să încurajeze dezvoltarea sustenabilă etc.

\section{Exemple}

Inner-City Arts Campus - Michael Maltzan Architecture, 2008, Los Angeles, SUA (Pearson, 2009)

Dar fiind amplasamentul, proiectul nu răspunde numai temei, ci şi unor probleme de ordin social şi politic cu care comunitatea din Skid Row, Los Angeles se confrunta. Prin programe de artă şi performance, Inner-City Arts deserveşte un număr mare de copii şi tineri în situaţii de risc (proveniţi din familii sărace sau chiar fără adăpost), asigurându-le nu doar un loc în care învaţă prin artă, ci şi un loc în care sunt în siguranţă, în care îşi construiesc identitatea, comunică şi învaţă ce înseamnă responsabilitatea socială faţă de comunitate - „un loc al speranţei, un nou început pentru copiii cu probleme" (Pearson, 2009).

R/GA Headquarters - Foster+Partners, 2017, New York, SUA (Hustwit, 2016; R/GA / Foster + Partners, 2017)

Foster+Partners inovează, prin acest proiect, conceptul de spaţiu de birouri în strânsă legătură cu domeniul de activitate al beneficiarului - R/GA oferă servicii de asistenţă a firmelor în vederea adaptării la noile tehnologii şi la schimbări în obiceiurile de consum. Proiectul se dezvoltă în jurul ideii de intersecţie a spaţiului fizic şi spaţiului digital, punând accent pe nevoile angajaţilor şi clienţilor (luând în considerare inclusiv posibilităţi de adaptare în timp), pe intersecţii şi comunicare (voite sau întâmplătoare). Prin proiect se are în vedere susţinerea creativităţii, inovaţiei, creşterea performanţelor prin creşterea calităţii spaţiului.

Médecins du Monde, Anderlecht, Belgia (Bruno et al., 2018)

Proiectul, dezvoltat în cadrul laboratorului de cercetare aplicată şi critică urbană Metrolab Brussels, vizează facilitarea construirii unei comunităţi în Cureghem, Anderlecht, pornind de la schimbările sociale şi dezvoltările urbane ce generează sau se aşteaptă a genera tensiuni. Plecând de la nevoia creşterii nivelului economic al populaţiei din Cureghem care să permită, mai apoi, dezvoltarea infrastructurii sociale şi de la probleme de accesibilitate la sistemul medical, echipa şi-a conturat propunerea în jurul scenariului extinderii dreptului la servicii de sănătate pentru a acoperi un context altfel informal - cel al oamenilor fără adăpost, al refugiaţilor, imigranților fără forme legale etc. 


\section{Recomandări bibliografice}

Jaffe, R., \& de Koning, A. (2016). Introducing Urban Anthropology. Routledge.

Volumul abordează teme actuale de antropologie în strânsă legătură cu spaţiul urban în care se manifestă, explicând mecanisme de constituire şi subliniind complexitatea fenomenelor sociale asociate. Teme: locuri urbane; mobilităţi urbane; viaţa socială în spaţiul public; economii urbane; consum, petrecerea timpului liber şi stiluri de viaţă; oraşe şi globalizarea; planificarea oraşului; oraşe, cetăţenie şi politici; violenţă, securitate şi control social.

Henckel, D., Thomaier, S., Könecke, B., Zedda, R., \& Stabilini, S. (Eds.). (2013). Space-Time Design of the Public City (Vol. 15). Springer.

Volumul dezvoltă o serie de perspective spaţio-temporale asupra oraşului, centrate pe locuitori şi utilizare. Teme: ritmuri urbane şi diversitate (utilizările oraşului raportate la timp, recuperarea nopţii în context urban); mobilitate şi acces (spaţiul urban în mişcare, dreptate socială); politici urbane referitoare la timp (dreptul la oraş).

\section{Hill, J. (2003). Actions of architecture: Architects and creative users. Routledge.}

Autorul piveşte arhitectura a fi (re)creată prin utilizare şi consideră că utilizatorul şi creativitatea sa în interpretarea şi utilizarea spaţiului trebuie luate în considerare de către arhitect în procesul de proiectare.

\section{Referinţe}

Augustin, S., \& Coleman, C. (2012). The Designer's Guide to Doing Research: Applying Knowledge to Inform Design. John Wiley \& Sons, Inc.

Bruno, A., de Azevedo Nascimento, E. A., Milic, P., Orlek, J., Ranzato, M., Théréné, M., Thielemans, F., Tilman, A., Van Ngoc, H., \& Vignes, M. (2018). Site 2. Médecins du Monde: Collective health. În M. Berger, B. Moritz, L. Carlier, \& M. Ranzato (Ed.), Designing Urban Inclusion (pp. 78-99). L.Capitan.

Colleoni, M. (2013). Mobility, Accessibility and Social Equity: A Comparative and Interdisciplinary Empirical Study in the Metropolitan Areas of Milan, Bologna and Turin. În D. Henckel, S. Thomaier, B. Könecke, R. Zedda, \& S. Stabilini (Ed.), Space-Time Design of the Public City (Vol. 15, pp. 137-156). Springer.

Cruz, T. (2016). Returning Duchamp's Urinal to the Bathroom? On the Reconnection between Artistic Experimentation, Social Responsibility and Institutional Transformation. În M. Fraser (Ed.), Design Research in Architecture: An Overview. Routledge.

Gutiérrez, F. R. (2013). City, Urbanism, Social Sustainability and the Right to the City. În D. Henckel, S. Thomaier, B. Könecke, R. Zedda, \& S. Stabilini (Ed.), Space-Time Design of the Public City (Vol. 15, pp. 217-225). Springer.

Hill, J. (2003). Actions of architecture: Architects and creative users. Routledge.

Hustwit, G. (2016). Workplace: The Connected Space Documentary. https://www.rga.com/about/workplace

Jaffe, R., \& de Koning, A. (2016a). Consumption, leisure and lifestyles. În Introducing Urban Anthropology (pp. 87-100). Routledge.

Jaffe, R., \& de Koning, A. (2016b). Introducing Urban Anthropology. Routledge.

Jaffe, R., \& de Koning, A. (2016c). Urban mobilities. În Introducing Urban Anthropology (pp. 41-54). Routledge. 
Kuoppa, J. (2013). Beyond Vague Promises of Liveability: An Exploration of Walking in Everyday Life. În D. Henckel, S. Thomaier, B. Könecke, R. Zedda, \& S. Stabilini (Ed.), Space-Time Design of the Public City (Vol. 15, pp. 157-170). Springer.

Mareggi, M. (2013). Urban Rhythms in the Contemporary City. În D. Henckel, S. Thomaier, B. Könecke, R. Zedda, \& S. Stabilini (Ed.), Space-Time Design of the Public City (Vol. 15, pp. 3-20). Springer.

Mendes, M. M., Sá, T., \& Cabral, J. (Ed.). (2017). Architecture and the Social Sciences-Inter-and Multidisciplinary Approaches between Society and Space. Springer. https://www.springer.com/us/book/9783319534763

Miciukiewicz, K., \& Vigar, G. (2013). Encounters in Motion: Considerations of Time and Social Justice in Urban Mobility Research. În D. Henckel, S. Thomaier, B. Könecke, R. Zedda, \& S. Stabilini (Ed.), SpaceTime Design of the Public City (Vol. 15, pp. 171-185). Springer.

Pearson, C. A. (2009, februarie 19). Inner-City Arts, Phase III. Michael Maltzan designs a place of hope and creativity for Inner-City Arts in Los Angeles. Architectural Record, 197(2). https://www.architecturalrecord.com/articles/8145-inner-city-arts-phase-iii

R/GA / Foster + Partners. (2017). [Foster + Partners]. https://www.fosterandpartners.com/projects/rga/

Stickells, L. (2008). Flow Urbanism. The heterotopia of flows. În M. Dehaene \& L. de Cauter (Ed.), Heterotopia and the City: Public Space in a Postcivil Society (pp. 247-257). Taylor \& Francis e-Library.

Tonkiss, F. (2013). Cities by Design: The Social Life of Urban Form (1 edition). Polity. 